\title{
Competitive Diamond of Artisanal and Small Scale Gold Mining Industrial Cluster in Lombok Island, Indonesia
}

\author{
Lalu M. Furkan ${ }^{1, *}$, Baiq Handayani $R^{2}$, Emilia Septiani ${ }^{3}$
}

\author{
${ }^{1}$ University of Mataram, Mataram, Indonesia \\ ${ }^{2}$ University of Mataram, Mataram, Indonesia \\ ${ }^{3}$ University of Mataram, Mataram, Indonesia \\ ${ }^{*}$ Corresponding author. Email: lalu.furkan@unram.ac.id
}

\begin{abstract}
This research clarifies the competitive diamond of the Lombok ASGM industrial cluster. The Lombok ASGM industry is concentrated in Sekotong and Gunung Prabu areas. In order to achieve the research objective, a field survey had been conducted. In-depth interview with the miners, gold buyer, NGO, women helper, Gelondong residents, chief of the village, government, and surrounding communities was conducted. The result shows government and Balifokus/Nexus NGO play a significant role in the ASGM industry competitive diamond. The government should provide a set of regulations to formalize the ASGM industry for innovation drivers. While NGO Balifokus/Nexus concerns about technology shifting to eco-friendly based on the evidence explained in the paper.
\end{abstract}

Keywords: competitive diamond, artisanal small scale gold mining, industrial cluster.

\section{INTRODUCTION}

Gold is a shining commodity where many gold producers come from the legal and illegal gold mining industry. The artisanal and smallscale gold mining industry is primarily a typical illegal gold mining industry spread all over Indonesia, including Lombok island. While cluster refers to a group of interconnected companies concentrated in one specific geographic area linked by commonalities and complementarities (Porter 1998). Gold plays an important role in many events and rituals; therefore, its production often negatively impacts social lives and the ecosystem (Ali 2009, Hilson 2014). The rising demand of the gold industry could be seen from its supply perspective. About $48 \%$ of the gold ore supplies the gold shop (World Gold
Council 2014). Illegal miners often use mercury amalgam for gold processing in the ASGM industry. Consequently, the ASGM industry is a primary source of the world's mercury pollution (UNEP 2013).

Unfortunately, when the global mechanism works systematically to reform the ASGM industry, it cannot be followed by other sectors. This is probably caused by the weak agreement terminology used. Hence, it requires strong commitment and consensus to run the agreement. This might end the implementation gap among the parties, especially in developing countries with low capacities and interests to be opponents of illegal gold mining. Many parties agree with many regulations about illegal mining, but they have no power and capacity to execute those regulations (Siegel \& Veiga 2010). 
The capacity gap could be addressed by the technical assistance supervised by affiliated countries in terms of money, training, and technology transfer, but the Minamata convention's funding mechanism is voluntary. This might cause uncertain funding flows. Developing countries own abundant of the mineral have incentives to supply the large mining companies contributing taxes and royalties to the countries compared to the ASGM industry. The large mining companies and ASGM industry are often operating in a similar location; therefore, the large mining companies often lobby the government to readminister the ASGM industry regarding their scope of operation and eradicate them if possible. This might be conflicting with the Minamata Convention, where the ASGM industry should be admitted of their existence. Eradicating efforts of the ASGM industry tend to shift them into the black market. In fact, it is challenging to eradicate the ASGM industry. The competitive capacity of the ASGM industry involving men, women, and children to earn money for daily life. We are curious about the Lombok ASGM competitive diamond capacity. However, the study of the competitive diamond capacity was rarely found. This research aims to clarify the competitive diamond of the Lombok ASGM industry cluster.

\section{RESEARCH METHODS}

The Lombok ASGM industry was selected to be the research setting. Pelangan and Prabu village are among the most active of the ASGM industry in Lombok island. The Lombok ASGM industry was chosen because of some criteria. Firstly, the ASGM industry has taken much attention from the government and scholars. Secondly, the Minamata convention underlines that the ASGM industry should be recognized for its existence. Thirdly, the ASGM industry and tourism industry are in a specific area.
We employed an exploratory case study with the qualitative method. This method helps to explore the Lombok ASGM industry. There are two selected cases of the Lombok ASGM industry. Pelangan and Prabu village are located in West Lombok and Central Lombok regency. This might represent the Lombok ASGM industry concentration area with different industry characteristics. However, they are located along the southern coastline of Lombok island. We selected these two locations based on the following criteria. Firstly, The ASGM industry has been in operation since three years ago. Secondly, they have been profitable during the operation. Thirdly, they have been recognized as the Lombok ASGM industry concentration by the government.

This study was based on the primary data: archives, in-depth interviews. In-depth interviews were employed to collect information from the ASGM owner, illegal miners, head of the village, government, gold buyer and trader, NGO, villagers, politicians, policemen, woman helpers, and Gelondong owners. We collected information about their general perspectives of the ASGM industry. Whole pictures of the Lombok ASGM industry and its impacts and industry characteristics and mechanism were explained. The secondary data also supported this information through previous studies, websites, and archives to reveal the current status of the Lombok ASGM industry.

We analyzed data using the triangulation technique. Triangulation source of information was used to confirm data validity and reliability. Information from various informants was used to reveal the current status of the Lombok ASGM industry. We focused on similarities and differences among the two selected cases to identify emerging patterns and themes. 


\section{RESULTS AND DISCUSSION}

\subsection{ASGM industry in Lombok island}

\subsubsection{ASGM industry in Pelangan village}

ASGM industry in Pelangan village is located in Sekotong district, West Lombok regency. There are some spot areas of the ASGM industry in Sekotong district such as CendikManis, Medang, Gili genting, Elak Juring, Tembowong, Labuan Poh, Gunung Ketapang and Pelangan. However, Pelangan village was selected since it is among the busiest ASGM industries in Sekotong districts. They have a similar pattern of business operation in the Sekotong district. The history of the ASGM industry in Sekotong district was begun at the Pelangan village. This story was told by the head of Pelangan village officer as follows:

"The history of the ASGM activities in Pelangan village, Sekotong district, started when PT Indotan did exploration activities in Bukit raja and Bukit simba. Bukit raja was an inactive mining spot, while Bukit Simba was the first ASGM activity in Sekotong district. Thus, this was stopped since PT Indotan concession area had not reached economies of scale. The villagers realized the ASGM operation just after PT Indotan explored the three mining concession spot areas such as Bukit Raja, Tibuserai, and Bukit Simba. Hence, the villagers started the ASGM activities surrounding PT Indotan concession area. About 50 to $60 \%$ of the male and female population of the Pelangan village work in the ASGM industry. This was caused by the closed distance of the ASGM spot area in Bukit Simba and the village office. It takes about 10 minutes driving. Before the ASGM activities, the villagers earned money as farmers, fishermen, and any other profession. The ASGM activities tend to decrease drastically compare to prior since the number of gold reserves declined. On the other side, mercury has been illegal and more expensive; therefore, it was replaced by the Sianida. The miners tend to legalize the ASGM industry. This way might help the ASGM business for technical assistance, machine, and technology support from the government."

Based on the information above, we realized mercury has been so essential for the ASGM industry. It was needed for gold recovery, but it had been illegal. Mercury came from cinnabar ore, which was mined in Kalimantan Tengah, Sulawesi Tenggara and Pulau Seram. The Cinnabar ore is exported to many countries such as the Netherlands, Taiwan, Hongkong, and Singapore. While cinnabar ore was also sent to West Java, such as Suka Bumi, Bekasi, and the East Java area, to be processed into liquid and distributed to the ASGM spot area all over Indonesia. The ASGM owner in Pelangan village also told the history of the ASGM industry and mercury usage

"The ASGM activities were introduced for the first time by pak Iwan as he took some types of the stones and used a plate to catch the gold. This made the villagers enthusiastic at the beginning. The ASGM industry used mercury to gold recovery between 2007 and 2011. Thus, carbon was introduced with the media of tonk just after 2011. About 100 sacks of mud produced with media of gelondong were inserted into media of tonk mixed by the carbon. Thus, 100 sacks of mud in the media of tonk can produce 100 grams of gold. Hence, they sell the gold in Sekarbella village and the gold shop of the Melati."

We could see from the evolution of the substance for gold recovery using mercury and carbon. Using carbon with media of tonk is much more profitable from this viewpoint because it might recover more gold than using gelondong techniques. Transfer knowledge and technology used for ASGM activities in Sekotong generally and Pelangan mentioned explicitly by the NGO director who focused on the forest greening and replanting as follows:

"The villagers knew the ASGM activities in central Sekotong and West Sekotong 
around 2010. Bukit Simba at Pelangan village was the first ASGM spot area in Sekotong. Suddenly, he knew a group of miners from West Java such as Tasik Malaya and Lembang, Kalimantan, and Sumatra, which the miners from West java dominated. These groups started the ASGM activities from the exploration spot area done by PT Indotan. The company canceled the exploration since the gold reserve did not meet the mining economies of scale. Hence, the group of miners from West Java, Sumatra, and Kalimantan began the ASGM activities on the exploration site, which the company did.

They found it was successful in Bukit Simba; therefore, many people came and joined the ASGM activities at Bukit Simba. The ASGM activities were spread and concentrated in some spot areas in Sekotong. The miners from West Java transferred the knowledge of the mining techniques and skills to find the gold path. Some local people involved direct and indirect mining activities while others are regulators, investors, buyers, and sellers".

\subsubsection{ASGM industry in Prabu village}

The ASGM activities in Prabu village have different industry characteristics and processing to Sekotong ASGM activities. Historically, the ASGM activities in Prabu village were introduced by the ASGM from China. The company started the ASGM activities in 2016 and introduced them to the local people. Many local people were interested and joined the ASGM activities according to their methods and techniques for gold recovery. According to the Prabu village officer, when local people had been transferred the knowledge and skills of the mining techniques, they reported the Chinese ASGM business to the immigration, and the local people have continued mining. The ASGM industry in Prabu village has different mining techniques. They have used excavators with a maximum 5-meter capacity to dig the ground. The ground soil and stones were processed with no mercury but potassium, carbon, and calcium. This method and techniques were more environmentally friendly compared to Sekotong ASGM methods and techniques. They also did not make any holes on the ground and follow the gold path until a hundred meters under the ground. The Prabu village officer further explained that the ASGM activities might change the socio-economic condition of the Prabu villagers. The ASGM owners might earn Rp. 75,000,000 per week with five stone crushers. While others might earn Rp. $100,000,000$ per week. The simple stone crusher operator might earn Rp. 2,000,000 per week. While on average, the miners might earn Rp. 5,000,000 per week. The ASGM industry at the Prabu village might change their socio-economic condition drastically. They build villas to support the tourism industry since the Prabu village is very closedistance to the special economic zone of Mandalika. Therefore, there are many villas and homestays along the main street of Prabu village. While others could build a new house, house-renovation, new store business, buy car and motorbike, and even they send the family study in Java island. However, the massive ASGM activities have a negative impact on environmental degradation. Deforestation, land sliding, water pollution, and air pollution might cause disaster in the short and long term.

\subsection{Lombok ASGM industrial cluster}

\subsubsection{Firm rivalry and strategy}

Rivalry among the miners is common as there are miners from West Java such as Tasikmalaya, Sukabumi, Lembang, and surrounding areas dominating the Sekotong ASGM activities. We could also find miners from Sumatra, Kalimantan, and Aceh. They came to Sekotong from the informal networks among the miners and financed by the West 
Java investors. The West Java miners built the tent on the hill or other mining spot areas. Thus, they introduced themselves and their activities to the local people. They also offered the locals to join mining and, if possible, to be the investor with a profitsharing mechanism. When the local people have the mining skills and techniques, they could be independent miners. This might contribute to the more severe competition and strategy to succeed. Recently, the amount of gold reserve in Sekotong shows a declining trend. This forces the West Kava miners to move probably to Sumbawa island or any other places. Hence, the local miners play their role in the Sekotong ASGM spot area.

\subsubsection{Factor conditions}

The ASGM industry in Pelangan village and Prabu village are located in the Southern part of Lombok. These locations are blessed with the gold-mineral reserve. Bukit Simba was among the first ASGM activities in Sekotong located in the Pelangan village. This ASGM spot area used to be the concession area of the PT Indotan. Based on the data analysis, the amount of the gold reserve at Bukit Simba did not meet economies of scale for exploration; therefore, it was canceled. However, the ASGM activities emerged on the concession spot area and many others ASGM spot areas in Sekotong. The ASGM activities have also emerged in Prabu village since 2016. The Prabu village is located next to Kuta Mandalika where special economic zone for the tourism industry. The ASGM industry seems to be conflicting with the tourism industry. These industries could not stand together. Therefore, the ASGM industry was stopped by law enforcement officers. The policemen call for those miners who are doing the mining operation.

\subsubsection{Demand condition}

Global demand for gold commodities is rising. Further, we might see some national state enterprises such as PT Antam, Tbk, and some other companies engage in the ASGM industry for the gold supply. The Lombok ASGM industry could easily sell their gold to the gold buyers, spreading all over the ASGM mining site. Even the gold buyer came to the ASGM mining activities to buy directly from the ASGM miners. The gold buyer would be happy to buy the gold for the ASGM miners for any amount of gold offered. The gold buyer and the gold shop often finance the ASGM activities by sharing profit and benefits agreements. Most local gold buyers and the gold shop come from Sekarbela village, Melati gold shop, and Tantai gold shop located in Mataram. They have their networks to reach the ASGM gold with various schemes and methods. The gold buyers from Mataram would sell the gold to Bali and Surabaya buyers. From this area, they probably will sell to Jakarta or foreign buyers.

\subsubsection{Related and supporting business/networking}

The ASGM industry has become an international issue. About 130 countries signed the United Nation's Minamata Convention to reduce the emission and use of mercury (UNEP, 2013; Xu et al., 2015). The most significant remaining use of mercury is from the ASGM industry all over the world. The liquid mercury used in the gold recovery at the ASGM activities came from the cinnabar industry. The cinnabar mining siteis located in Central Kalimantan, Sulawesi Tenggara, and Seram island. The cinnabar ore was sent to West Java, Bekasi, and East Java to become liquid mercury using the conventional method and distributed to all the ASGM spot areas all over Indonesia. Since mercury is a global pollutant used mostly in the Lombok ASGM industry, it is extensively studied. Balifokus/ Nexus NGO researched 
mercury emission in Sekotong and its impact. It engaged researchers from the University of Mataram, especially in the medical field, to control the impact of the ASGM industry with their mercury usage. Another researcher from Kyoto University also focused on the mother and their baby's health when exposed to mercury. From the viewpoint of corporate social responsibility, PT $\mathrm{X}$ concerns the role of actors involved in the ASGM activities. This party has provided some facts based on the research findings. These findings are powerful tools for the government in order to provide policies related to the ASGM industry. Policy mapping might control the industry in great detail. Other actors involved in the ASGM industry are gold buyer, gold shop, investor or boss, miners, taxi bike, helper, stone crusher, politician, media, mercury dealer, mercury producer, cinnabar producer and seller, government officer, law enforcement officer, café business, tourism business, and state or private corporations.

\section{CONCLUSION}

This study clarifies the competitive diamond of the Lombok ASGM industry cluster. This study shows that the government plays an essential role in the Lombok ASGM industry cluster. It has a wide range of regulations on the Lombok ASGM industry and large mining industry. However, the government has no regulation to formalize the ASGM industry. It is essential to promote the formal ASGM industry with strong regulation behind it. Hence, it promotes innovation and productivity in the regions. Thus, innovation on the Lombok ASGM industry cluster would be promoted by the complex network of the government-university-industry-communitiesmedia and other NGO and research institutions. Bali focus/ Nexus is an essential intermediary for technology shifting to eradicate mercury usage on the ASGM industry cluster.

\section{REFERENCES}

Ali, S. 2009. Treasures Of The Earth Need, Greed, and a Sustainable Future. Connecticut: Yale University Press.

Hilson, G. 2014. Constructing Ethical Mineral Supply Chains in Sub-Saharan Africa: The Case of Malawian Fair Trade Rubies. Development and Change 45(1). DOI: 10.1111/dech.12069.

INCAM, 2013. Indonesian Centre for Artisana Mining (INCAM) extended concept note. Internal report

Porter, M.E. 1998. Competitive Advantage: Creating and Sustaining Superior Performance. New York: The Free Press.

Siegel,S. \& Veiga,M.M. 2010. The myth of alternative livelihoods: artisanal mining, gold, and poverty. Int. J. Environ. Poll. 41(3/4): 272-288.

UNEP. 2013. Technical backgroundreport for the global mercury assessment. Arctic monitoring and Assesment Programme, Oslo.. Working papers. Norway/UNEP.

World Gold Council. 2014. Gold Demand Trends Full Year 2014. Retrieved from https://www.gold.org/goldhub/research/golddemand-trends/gold-demand-trends-full-year-2014 